\title{
Multiband Handset Antenna With a Parallel Excitation of PIFA and Slot Radiators
}

\author{
Jaume Anguera, Senior Member, IEEE, Iván Sanz, Josep Mumbrú, and Carles Puente, Member, IEEE
}

\begin{abstract}
A handset antenna technique combining a parallel excitation of a PIFA and a slot is presented. The number of frequency bands is given by the sum of bands given per each radiator which can be controlled independently. Component interaction (battery, display, and speaker) is analyzed to determine the best place to mitigate performance degradation. Finally, a concept featuring a small footprint $\left(39 \times 11 \mathrm{~mm}^{2}\right)$ and low profile $(2 \mathrm{~mm})$ is proposed for multiband operation.
\end{abstract}

Index Terms-Component interaction, handset antennas, multiband, planar inverted F antenna (PIFA), slot, specific absorption rate (SAR).

\section{INTRODUCTION}

$\mathbf{O}$ NE of the decisive aspects of a portable radio device, such as for instance a hand-held telephone or a wireless device is its volume and size. From the consumer perception, the overall volume, mechanical design, ergonomics and aesthetics of the phone are decisive. There is an increased trend in making thinner phones that can better fit inside a shirt or jacket pocket or a bag or case.

This need in making smaller, thinner phones enters into conflict with the trend of adding more features to the phone. On one hand, phones are increasingly adding components and features such as large color screens, digital cameras, digital music players, digital and analogue radio and multimedia broadcast receivers (FM/AM, DVB-H, ...) and come with a wider range of form factors (bar phones, clamshell phones, flip-phones, slider phones, ...). On the other hand, new cellular and wireless services are being added, which in some cases means that multiband capabilities are required (to feature several standards such as for instance GSM850, GSM900, GSM1800, GSM1900, UMTS) or that other connectivity components (for instance for Bluetooth, IEEE802, WiFi, WiMax, ZigBee, Ultrawideband). All these trends put an increasing pressure on the antenna specifications, which need to feature a small footprint, a thin mechanical profile, yet performing efficiently at several frequency bands [1]-[16].

Manuscript received December 08, 2008; revised August 03, 2009. First published December 08, 2009; current version published February 03, 2010.

J. Anguera is with the Department of Electronics and Telecommunications, Universitat Ramon Llull-Barcelona, Barcelona 08022, Spain and also with

Fractus, S.A., 08174 Barcelona, Spain (e-mail: jaumean@ salleurl.edu).

I. Sanz and J. Mumbrú are with Fractus, S.A., 08174 Barcelona, Spain.

C. Puente is with the Polytechnic University of Catalonia (UPC), Barcelona, Spain and also with Fractus, S.A., 08174 Barcelona, Spain.

Color versions of one or more of the figures in this paper are available online at http://ieeexplore.ieee.org.

Digital Object Identifier 10.1109/TAP.2009.2038183
Several techniques employing PIFA and slots have already appeared in the literature. In [17] authors present a slot on the ground plane to make the ground plane resonant at the same frequency than the PIFA. This way, a broadband behavior covering from $800-1230 \mathrm{MHz}$ approximately (SWR $\leq 3$ ) is obtained, that is, an antenna that fulfills at least the standards GSM850 (824-894 MHz) and GSM900 (880-960 MHz). In [18] a similar approach using a resonating ground plane is shown (design covers from 750 to $1250 \mathrm{MHz}$ approximately, SWR $\leq 3$ ). In [19], a design using multiple slots on the ground plane is studied in order to achieve a multiband behavior. In spite of the good reflection coefficient results, the proposed structure is difficult to be integrated into a handset phone due to battery, displays, and speakers, among others that can short-out the slots effect. To overcome the component integration problem, in [20]-[23] a similar design is proposed using a slot underneath the antenna area. The slot has two objectives: on the one hand to tune the ground plane to resonate at lower bands (around $900 \mathrm{MHz})$ as in [17], [18] obtaining a broadband behavior: (GSM850-900); on the other hand, the slot is designed in such a way that operates as a parasitic antenna resonating at the upper band $(1900 \mathrm{MHz})$. With a proper coupling between the slot and the PIFA [22], the bandwidth at the upper band is improved achieving GSM1800 (1710-1880 MHz), 1900 (1850-1990 $\mathrm{MHz}$ ), and UMTS (1920-2170 MHz).

Characteristic modes [24] have been used to give a good understanding on how the ground plane can be used to enhance the behavior of a handset antenna [25]-[27].

Other techniques have been proposed in [28]. In this case, the slot in not printed on the ground plane but embedded on the PIFA geometry. This technique creates an extra mode which enhances the bandwidth at the upper band covering from GSM900-1800 for the original design to GSM900-1800 and 1900 for the embedded-slot design.

In [29] a multiband low profile handset designed only with slot antennas is analyzed. Slots are not only useful to antenna design but also for damping undesired modes for EMC purposes [30]. Finally, other solutions employing monopole antenna for multiband purposes can be found in [31].

The objective of the paper is to present a handset antenna technique that combines a PIFA and a slot suitable for slim-profile and multiband cell-phones [32]-[34]. Although PIFA is not low profile compared with a slot-type antenna, the ground plane underneath facilitates component integration as it is demonstrated in this paper. This paper is a detailed extension as well as new data (component interaction) of the author's previous work presented in [34]. A similar concept based on a parallel excitation of two different antenna types (slot and monopole) can 

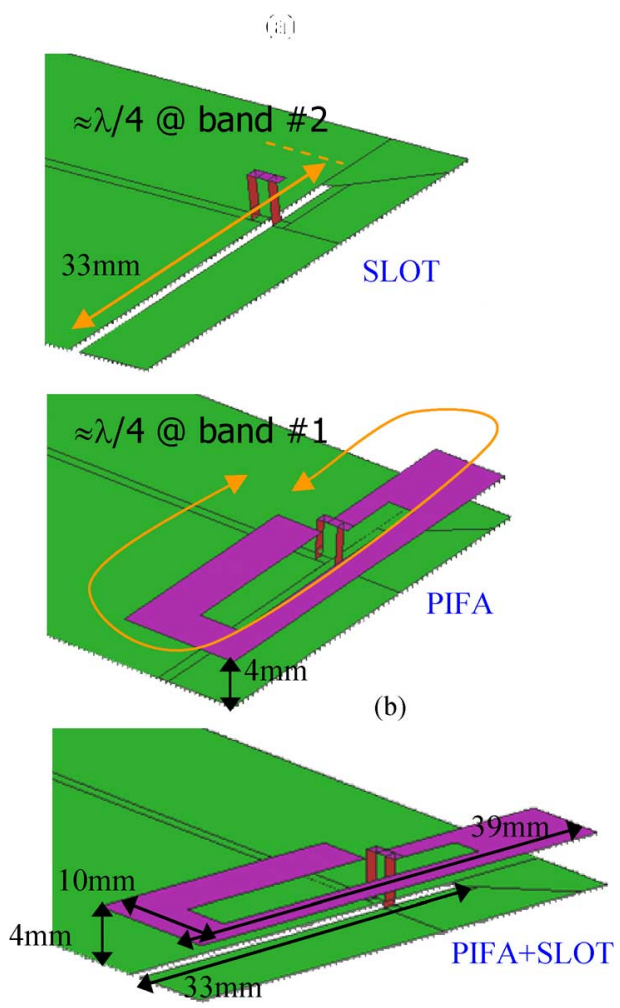

(c)

Fig. 1. Sequence showing the antenna concept. (a) a slot on the ground plane is tuned at $1.9 \mathrm{GHz}$ (band\#2); (b) PIFA is tuned at $900 \mathrm{MHz}$ (band\#1); (c) parallel excitation of both antennas (PIFA + Slot). Ground plane is $100 \times 40 \mathrm{~mm}^{2}$ for all cases.

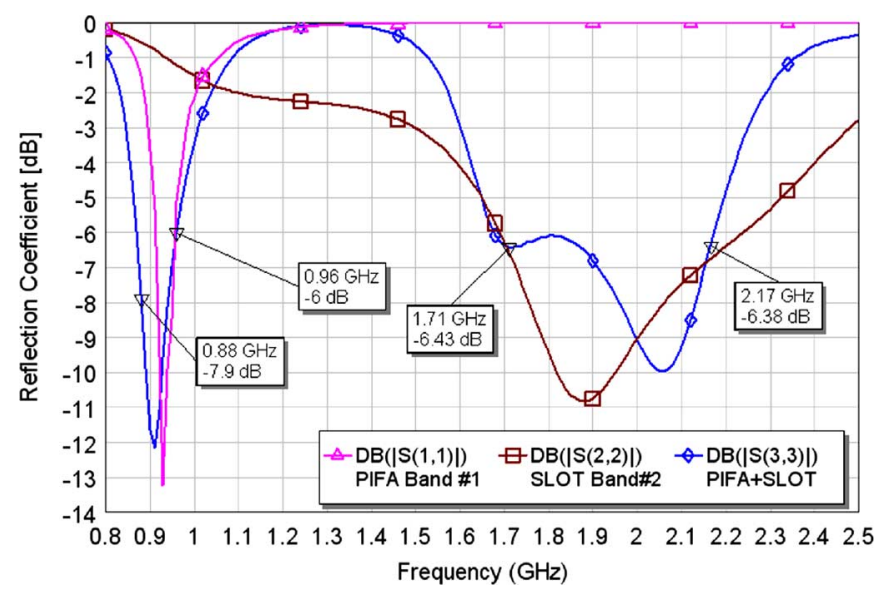

Fig. 2. Simulated reflection coefficient for the sequences shown in Fig. 1.

be found in [35] which also demonstrates to be very useful for multiband performance.

The paper is structured as follows: Section II explains the antenna concept. In Section III, simulation gives a physical insight into the antenna behavior. Component interaction (battery, display, and speaker) is analyzed in Section IV. Section V presents a low-profile design covering GSM900, 1800, 1900, UMTS, and S-DMB (2630-2655 MHz). Reflection coefficient, efficiency, radiation patterns, as well as SAR (specific absorption rate) results are shown. Finally, Section VI summarizes the work.

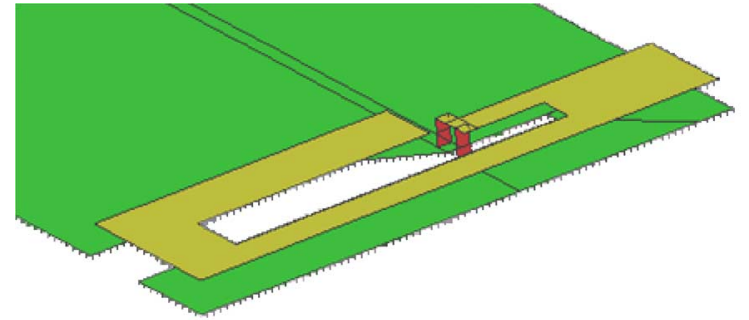

(a)

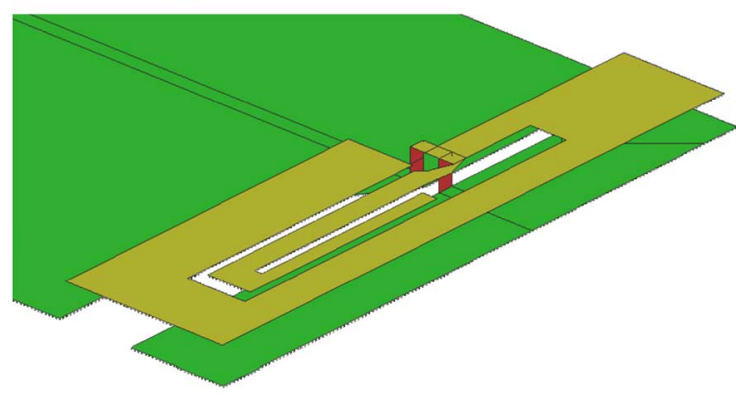

Dual branch PIFA+SLOT

Fig. 3. (a) Single branch PIFA + Slot; (b) Dual-branch PIFA +Slot: Adding an extra resonance to the PIFA antenna.

\section{ANTENNA CONCEPT}

One of the techniques to obtain multiband behavior for handset antennas is to create several resonant paths [2], [16]. Parasitic elements or increasing height may be used to enlarge bandwidth. However both techniques increase antenna volume which is especially prohibitive for the new generation of slim phones. Some solutions remove the ground plane under the antenna area resulting in a monopole type antenna. For these particular cases, once the ground plane under the antenna has been removed, cell-phone components such a camera, vibrator or speaker may degrade the antenna behavior [22]. The antenna technique presented here overcomes the problem of the small bandwidth for low profile PIFA and facilitates component integration.

An illustration on how the concept works is shown next. Fig. 1(a) depicts a slot on a ground plane having $100 \times 40$ $\mathrm{mm}^{2}$. In this case, the slot is excited around $1900 \mathrm{MHz}$. The obtained bandwidth covers GSM1800-UMTS at SWR $<3$. Fig. 1(b) shows a $900 \mathrm{MHz}$ PIFA on the same ground plane. The feeding mechanism is in the same position used to excite the previous slot. The bandwidth is quite poor as the PIFA height is only $4 \mathrm{~mm}$. Both designs are combined, that is, the PIFA and the slot share the same feeding mechanism [Fig. 1(c)]. It can be observed that the new antenna combines both reflection coefficients (Fig. 2). It is important to notice that bandwidth at $900 \mathrm{MHz}$ has been improved. A rationale for this may be found since some ground plane has been removed under the PIFA area reducing its quality factor. Another justification may be explained as the currents follow a larger path due to the slot on the ground plane. The ground plane wave mode gets closer to $900 \mathrm{MHz}$ reaching a better bandwidth [17]-[23]. For the combined solution, bandwidth $(\mathrm{SWR} \leq 3)$ at higher bands is similar as the single slot case. To increase the bandwidth at the second band, slot width may be increased [36]. 


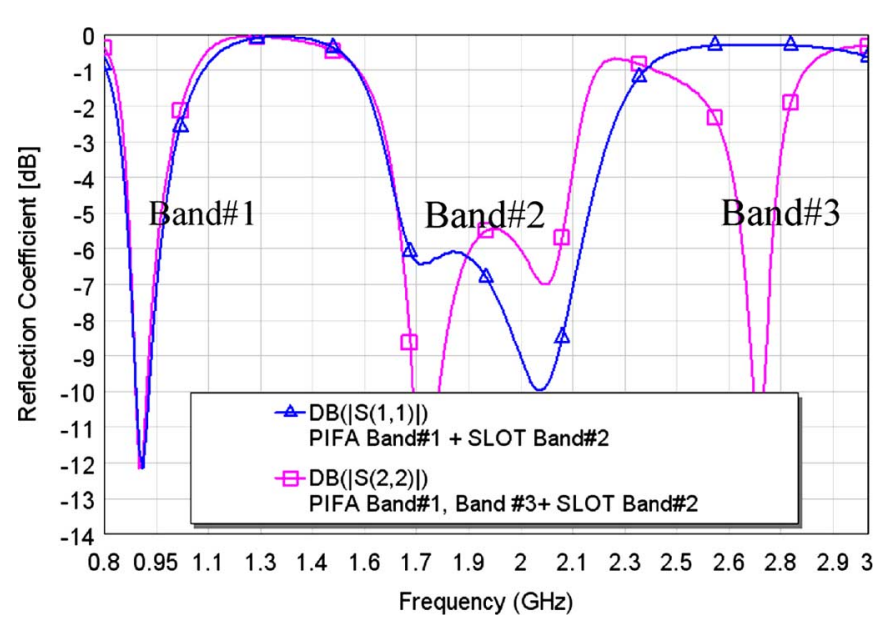

Fig. 4. Simulated reflection coefficient for the sequence shown in Fig. 3(a), (b).
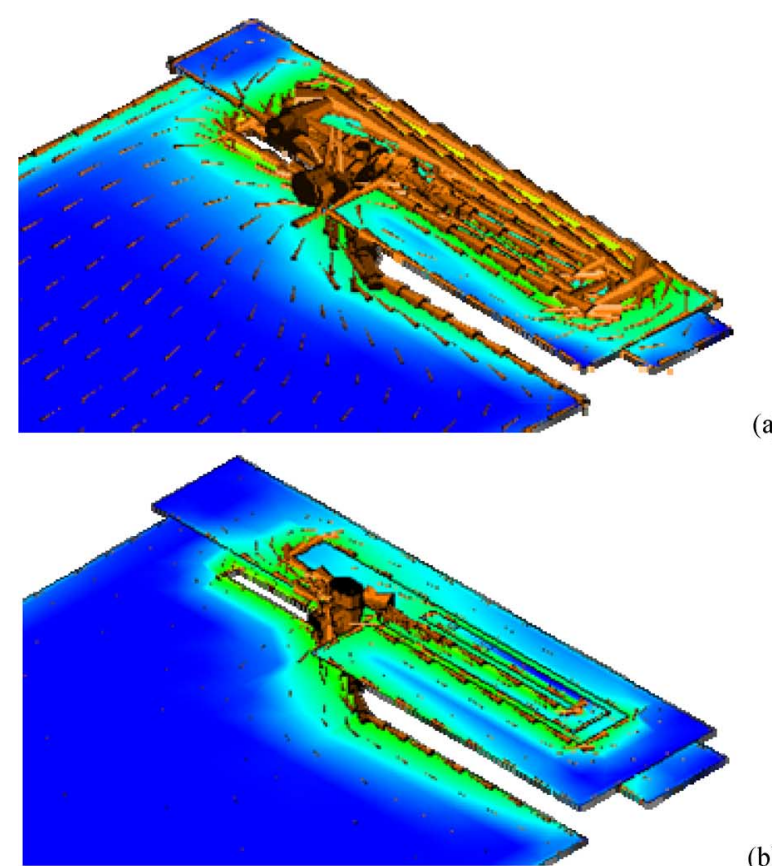

(a)

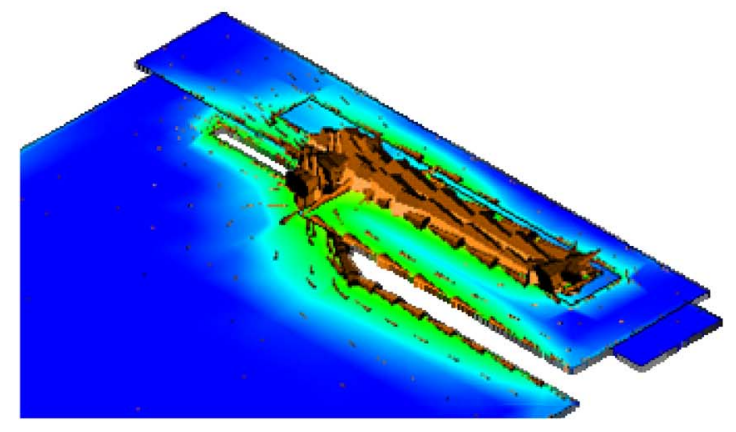

(b)

(c)

Fig. 5. Current distributions on the PIFA surface. (a) $900 \mathrm{MHz}$, (b) $1900 \mathrm{MHz}$, (c) $2600 \mathrm{MHz}$. The same dynamic range is used.

Since the PIFA has only one branch, used for the low band, the space can be reused to create a second path, that is, a new resonant frequency [33]. In this case, a new electrical path has

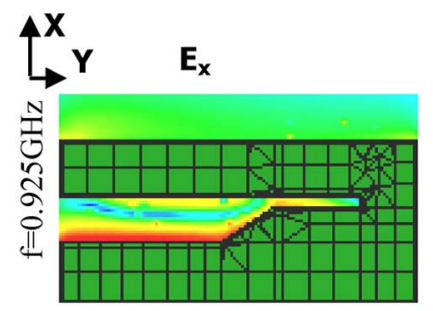

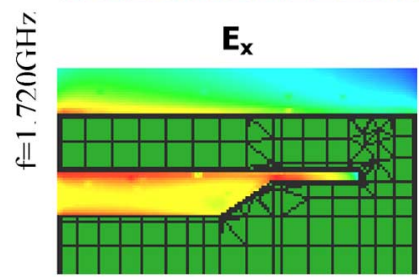

$\mathbf{E}_{\mathbf{x}}$

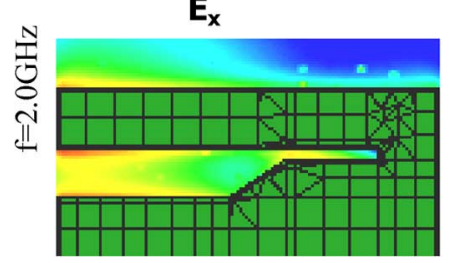

Fig. 6. Electrical field above the slot area.

been tuned at $2600 \mathrm{MHz}$ band which is centered at S-DMB approximately (Satellite Digital Media Broadcast); (Figs. 3, 4). For these two examples we can conclude that:

a) Number of bands $=$ number of PIFA bands + number of slot bands.

b) Bands due to the PIFA and the slot can be adjusted independently.

\section{CuRRENT AND Field Simulations}

Current distribution on the PIFA and electrical field on the slot has been computed using the IE3D MoM package to give an extra physical insight into the behavior of this antenna.

Fig. 5(a)-(c) shows the current distribution at 900, 1900, and $2600 \mathrm{MHz}$, respectively. It is remarkable that the PIFA is highly excited at $900 \mathrm{MHz}$ [larger branch at Fig. 5(a)] and at $2600 \mathrm{MHz}$ [short branch at Fig. 5(c)] whereas it is weakly excited at 1900 $\mathrm{MHz}$. The PIFA modes for both resonances are fundamental ones, that is, maximum of current distribution is at the feeding/ short area and the minimum is at the open edge.

To check the slot excitation, electrical field $\left(\mathrm{E}_{\mathrm{x}}\right.$ and $\left.\mathrm{E}_{\mathrm{y}}\right)$ on the slot area is computed at several frequencies Fig. 6. Notice that at $900 \mathrm{MHz}$ the slot is weakly excited compared to 1720 and $2000 \mathrm{MHz}$. At these frequencies, the field distribution corresponds to a quarter wave mode: minimum and maximum at the shorted and open edge, respectively having the illumination field $\left|\mathrm{E}_{\mathrm{x}}\right|>\left|\mathrm{E}_{\mathrm{y}}\right|$.

\section{COMPONENT INTERACTION}

This section analyses the effect on the antenna performance of three particular cell-phone components such as a speaker, a battery, and a display. 


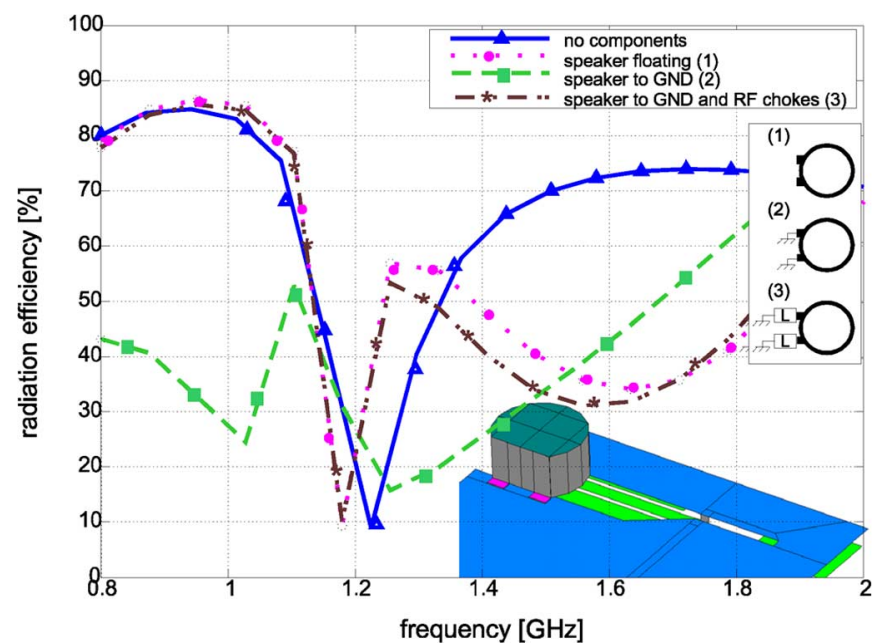

Fig. 7. Simulation to evaluate the effect to floating or connecting the speaker to the PCB.

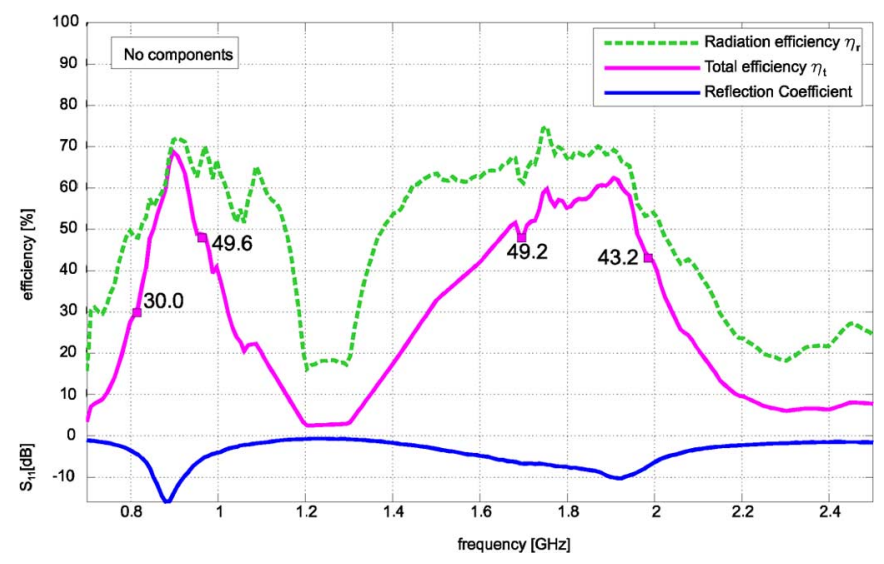

Fig. 8. Measured results without battery, speaker and display. Handset included both front and back plastic covers.

The characteristic of the components and their connection to the PCB or ground (GND) are described next.

- Speaker: circular shape of diameter $13 \mathrm{~mm}$. Floating.

- Battery: width is the same as the ground plane $=40$ $\mathrm{mm}$. Material: externally shielded with metal. Adhesive surrounding the whole structure. It is GND connected using the ground pad connection.

- Display: width is the same as the ground plane $=40 \mathrm{~mm}$. A thin metallic layer covers the back side of the display which is facing the slot radiator. It is GND connected.

The reason why the speaker has not been connected to the PCB is explained using simulations results (Fig. 7). The radiation efficiency is computed for four particular situations: without the speaker, with the speaker not connected, with the speaker connected to GND, and finally the speaker connected to the GND using $\mathrm{L}=100 \mathrm{nH}$. When the speaker is connected directly to the GND it degrades both lower and upper frequencies because the PIFA has more metallic part underneath and the slot is shielded. However, when the speaker is not connected, efficiency at lower frequencies is not degraded since the speaker is not an extension of the groundplane. The metal box of the speaker induces more ground effect to high-band slot and causes a poor efficiency. Since the speaker needs to be DC-connected to the GND, two RF chokes $(100 \mathrm{nH})$ are introduced to achieve it and at the same time at RF frequencies the speaker is disconnected. This way, the negative effects of the speaker are mitigated. Since the results for floating and RF chokes cases are practically the same, the following experiments uses the speaker in floating conditions.

The analysis carried out in Figs. 8-11 is explained next.

a) A PIFA-Slot prototype based on Fig. 3(a) operating at GSM850, 900, 1800, 1900 bands has been designed (see slot in Fig. 9 and PIFA in Fig. 10). Groundplane is 100 $\mathrm{mm} \times 40 \mathrm{~mm}$ and PIFA is $4 \mathrm{~mm}$ height.

b) Reflection coefficient and total efficiency $\left(\eta_{\mathrm{t}}\right)$ are measured using a plastic back-cover to emulate a more realistic scenario. Total efficiency is measured using 3D pattern integration with the Satimo Star-Gate 32 chamber at Fractus Lab.

c) Radiation efficiency $\left(\eta_{\mathrm{r}}\right)$ is calculated using (1)

$$
\eta_{r}=\frac{\eta_{t}}{1-\left|S_{11}\right|^{2}}
$$

It is important to outline that a component may shift reflection coefficient with minor changes in $\eta_{\mathrm{r}}$ which is true if the component introduces low losses or not degrades the antenna radiation; in other situations, a component may introduce losses or short out the antenna causing reflection coefficient to change and $\eta_{\mathrm{r}}$ to drop dramatically as it is shown next.

d) Aforementioned measurements are performed without components (Fig. 8) and with components at three different positions (Figs. 9-11). Note: for comparison purposes, 4 marks are included in all graphs indicating total efficiency at 824, 960, 1710, and $1990 \mathrm{MHz}$.

Fig. 9 shows the speaker effect when it is placed above the slot area. For position 1 neither the reflection coefficient nor $\eta_{\mathrm{r}}$ changes. Since the speaker is above the short-edge of the slot, the effect is negligible, meaning that the speaker may be integrated at this position without affecting antenna. However, as the speaker moves closer the open edge, there is a dramatic change in reflection coefficient as well as $\eta_{\mathrm{r}}$ at the higher band. This means that the speaker reduces radiation from the slot. Lower bands are affected in a much lesser way. This result corroborates data obtained from the simulation: slot is weakly excited at the lower bands.

Fig. 10 depicts the evolution of reflection coefficient, $\eta_{\mathrm{a}}$, and $\eta_{\mathrm{r}}$ for the following situations: (a) battery at $9 \mathrm{~mm}$, (b) $5 \mathrm{~mm}$, and (c) $0 \mathrm{~mm}$ from the PIFA inner edge. It is shown that the performance remains almost the same for b and c situations compared to non-component situation. However, at $0 \mathrm{~mm}$, reflection coefficient at GSM850-900 is shifted to lower frequencies and at the same time $\eta_{\mathrm{r}}$ drops degrading the antenna behavior. At GSM1800-1900 frequencies, antenna performance is slightly affected since the battery does not interfere with the slot area.

Fig. 11 explains the display effect when it is placed above the slot. The effect is pretty much the same as the speaker: to block the radiation from the slot. It is interesting to outline that in spite of the acceptable reflection coefficient at GSM1800-1900 bands, $\eta_{\mathrm{r}}$ is less than $30 \%$. The lower bands are weakly affected. 

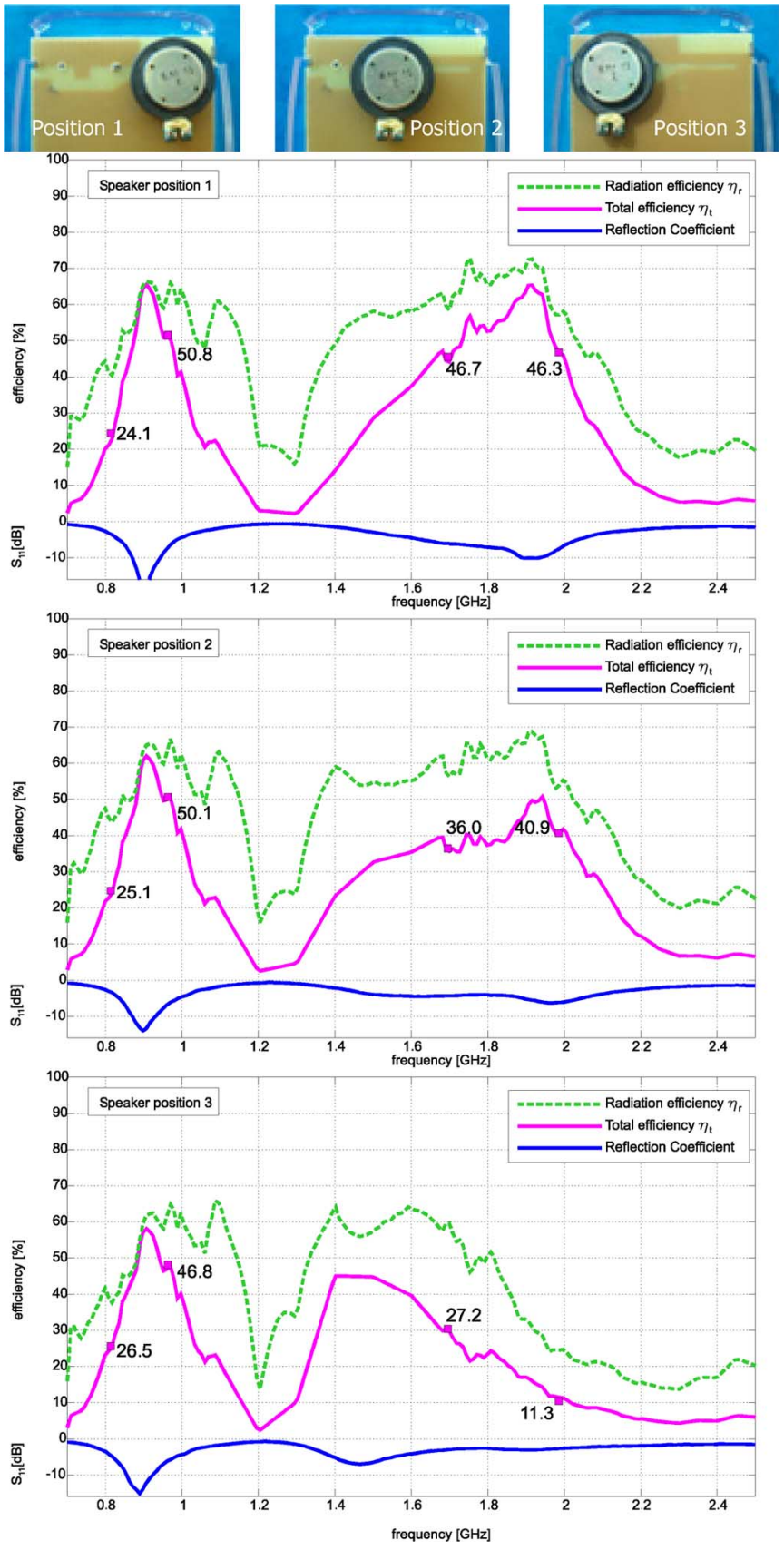

Fig. 9. Speaker effect.

From this experiment it is concluded that the slot should be kept free from the display, being this one a critical component.

We can outline that the slot is an attractive solution in terms of a low profile antenna, but it is sensitive when handset components are close to the slot aperture.

\section{SLIm HANDSET ANTENNA FOR MULTiBAND BEHAVIOR}

This section illustrates a particular design for pentaband (GSM900, 1800, 1900, UMTS, and S-DMB) behavior using the geometry depicted in Fig. 3(b). Physical implementation is shown in Fig. 12 and Fig. 13. Slot uses a wide aperture to enhance bandwidth especially at the upper bands (DCS-UMTS frequencies) since the slot is the antenna operating at these
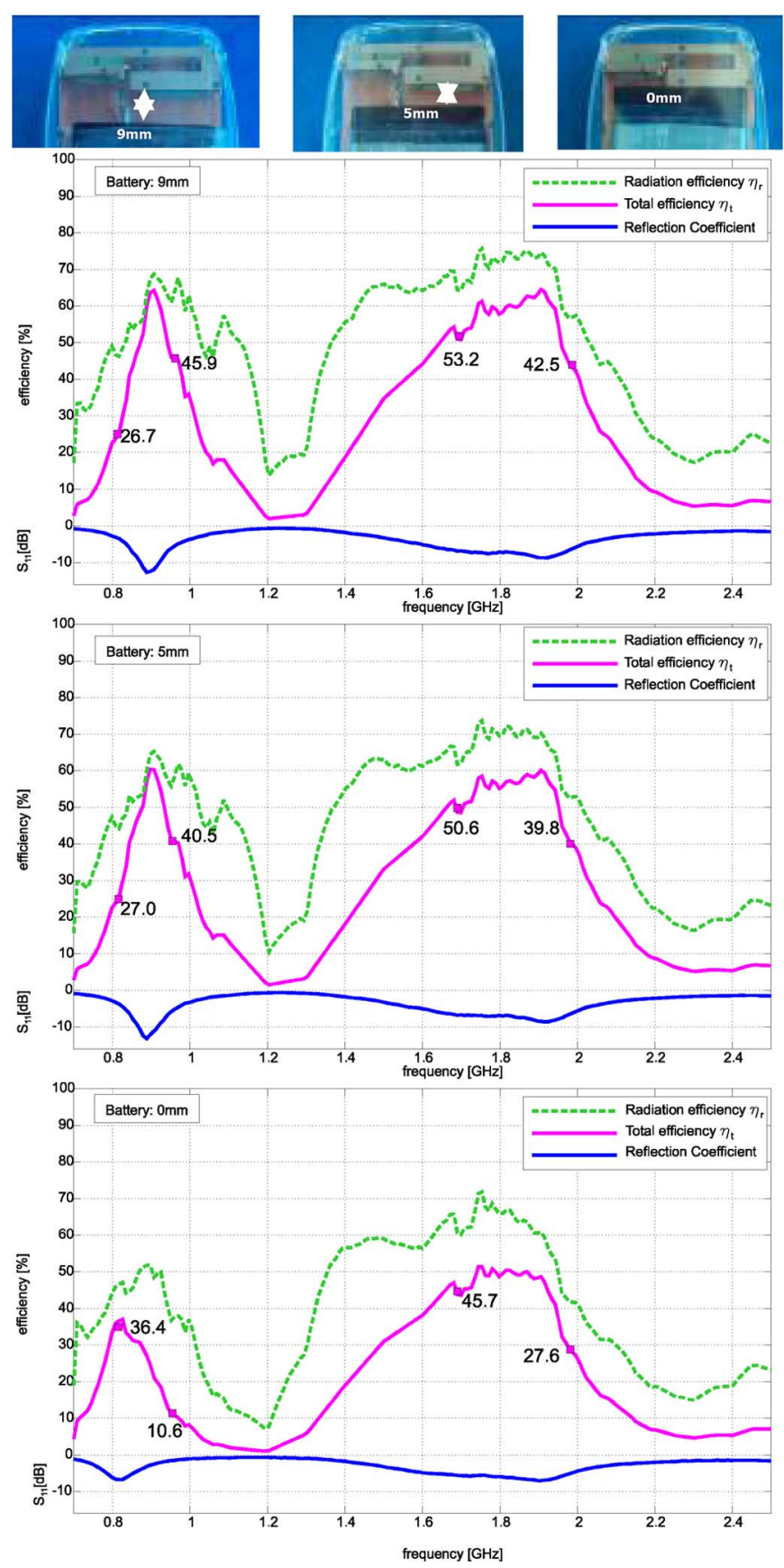

Fig. 10. Battery effect.

frequencies. Increasing the slot width may have a lateral effect on the PIFA at GSM900 frequencies since it has less ground plane underneath even the slot is not resonating at GSM900. This way, the PIFA has a partial ground plane which decreases its quality factor, that is, more bandwidth may be obtained.

A similar explanation may be observed for a partial grounded microstrip patch. When a slot is placed underneath the microstrip patch, it reduces the quality factor, and therefore the bandwidth of the antenna is increased [37].

More research needs to be done to include GSM850 band which should be achieved by either increasing slot width, PIFA height, or using broad banding networks. 

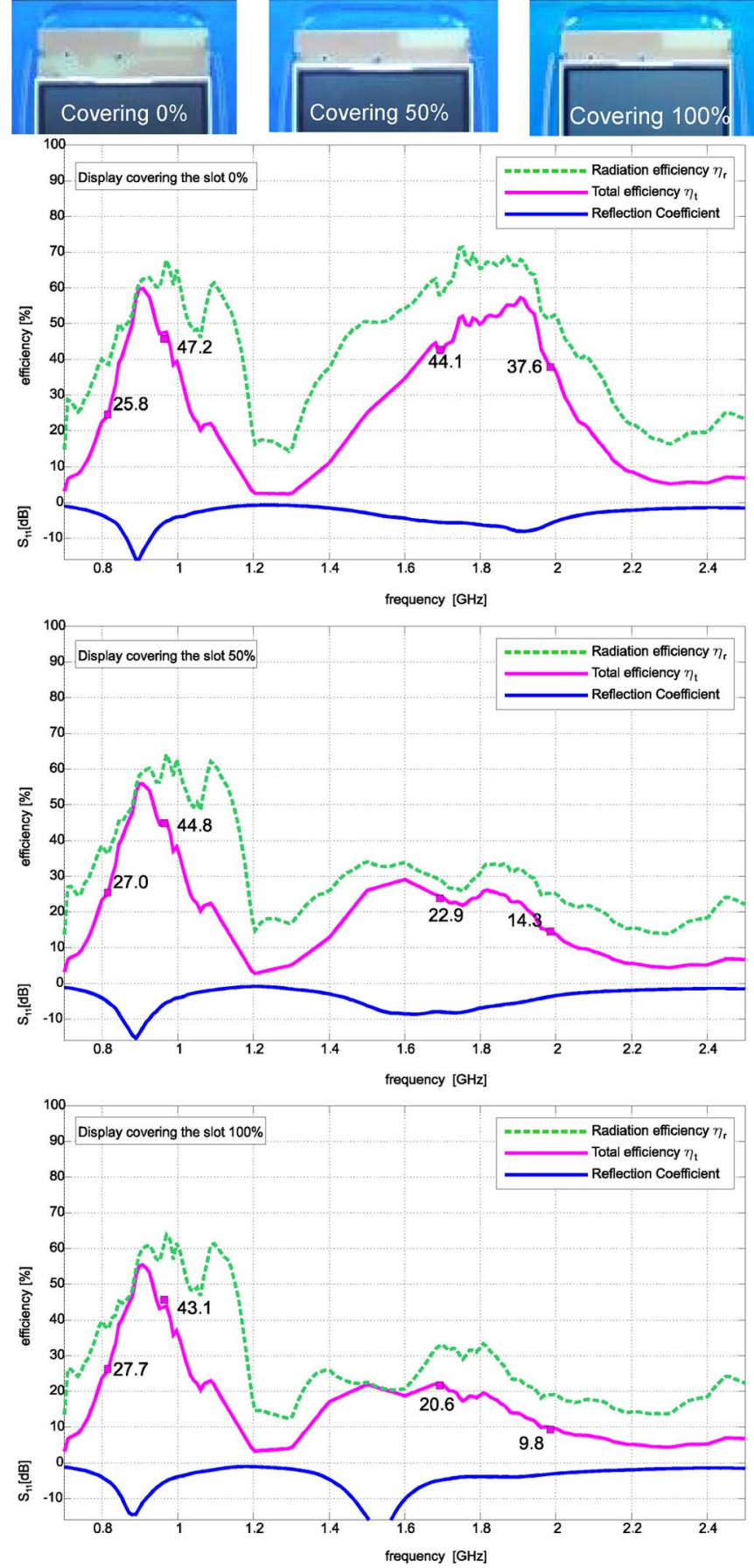

Fig. 11. Display effect.

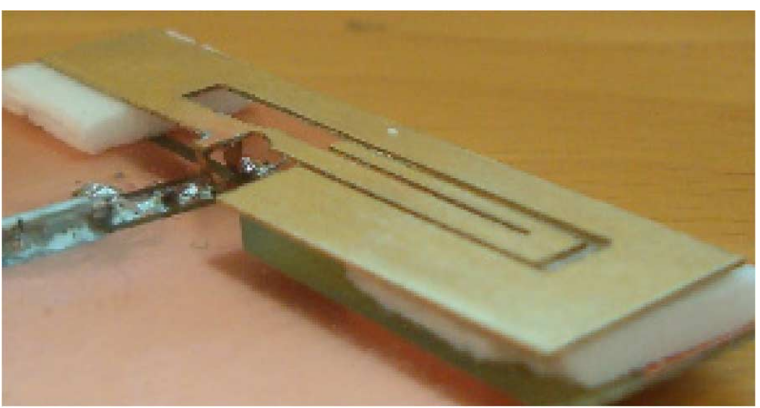

Fig. 12. Slim PIFA-Slot antenna: $39 \mathrm{~mm} \times 11 \mathrm{~mm} \times 2 \mathrm{~mm}(\mathrm{~h})$. Substrate is polymethacrylimide foam.

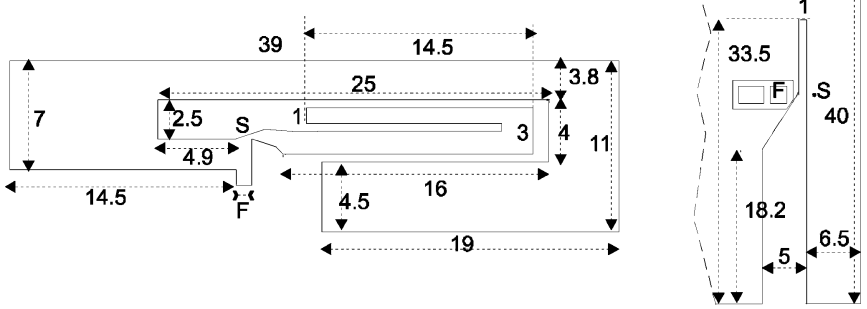

Fig. 13. PIFA and slot dimensions in mm. F: feeding point; S: short. F and S are two metal parts having $2 \mathrm{~mm}$ width $\times 2 \mathrm{~mm}(\mathrm{~h})$.

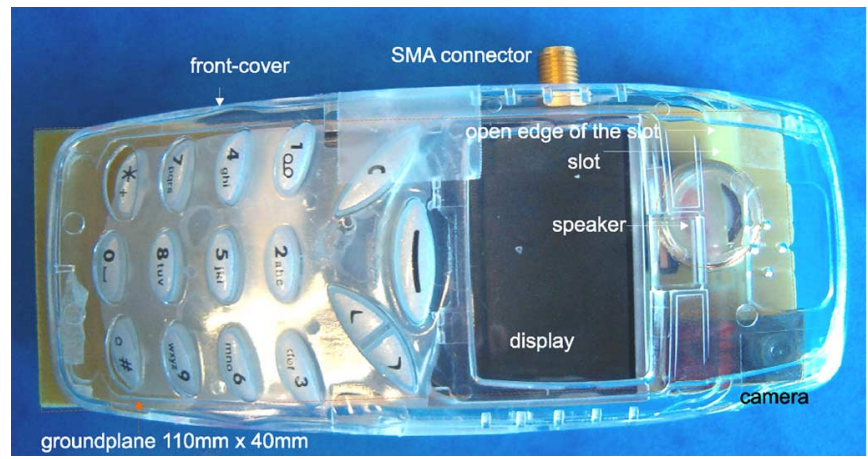

Fig. 14. The handset prototype using the PIFA-slot of Fig. 12. Speaker at position 2 (see Fig. 9). Battery at $9 \mathrm{~mm}$ from the PIFA. Display covering $0 \%$ the slot area.

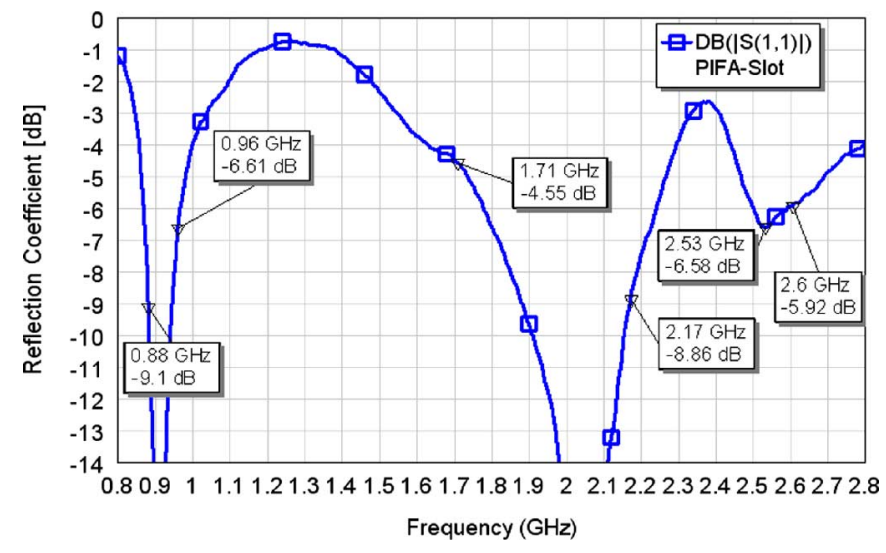

Fig. 15. Measured reflection coefficient for the antenna shown in Fig. 12.

Following the guideline presented in Section IV, a battery, a speaker, and a display have been attached to the ground plane. In addition, a camera has also been placed near the short-edge of the slot (Fig. 14). A front and a back cover are also taken into consideration for all the experiments.

Fig. 15 represents the reflection coefficient where it can be observed a good matching $\left(\mathrm{S}_{11}<-6 \mathrm{~dB}\right)$. At $1710 \mathrm{MHz}$, which is the starting frequency of GSM1800, matching may be further improved as there is enough room since the end part of UMTS $(2170 \mathrm{MHz}$ ) has almost $-9 \mathrm{~dB}$. It should be outlined that the PIFA height is only $2 \mathrm{~mm}$; as shown in previous section, increasing to $4 \mathrm{~mm}$ would be useful to include also GSM850 band being still a low profile PIFA [38]. 
TABLE I

RADIATION $\left(\eta_{\mathrm{r}}\right)$, TOTAL EFFICIENCY $\left(\eta_{\mathrm{t}}\right)$, AND REFLECTION COEFFICIENT FOR THE ANTENNA HAVING ALL THE COMPONENTS SHOWN IN FIG. 14

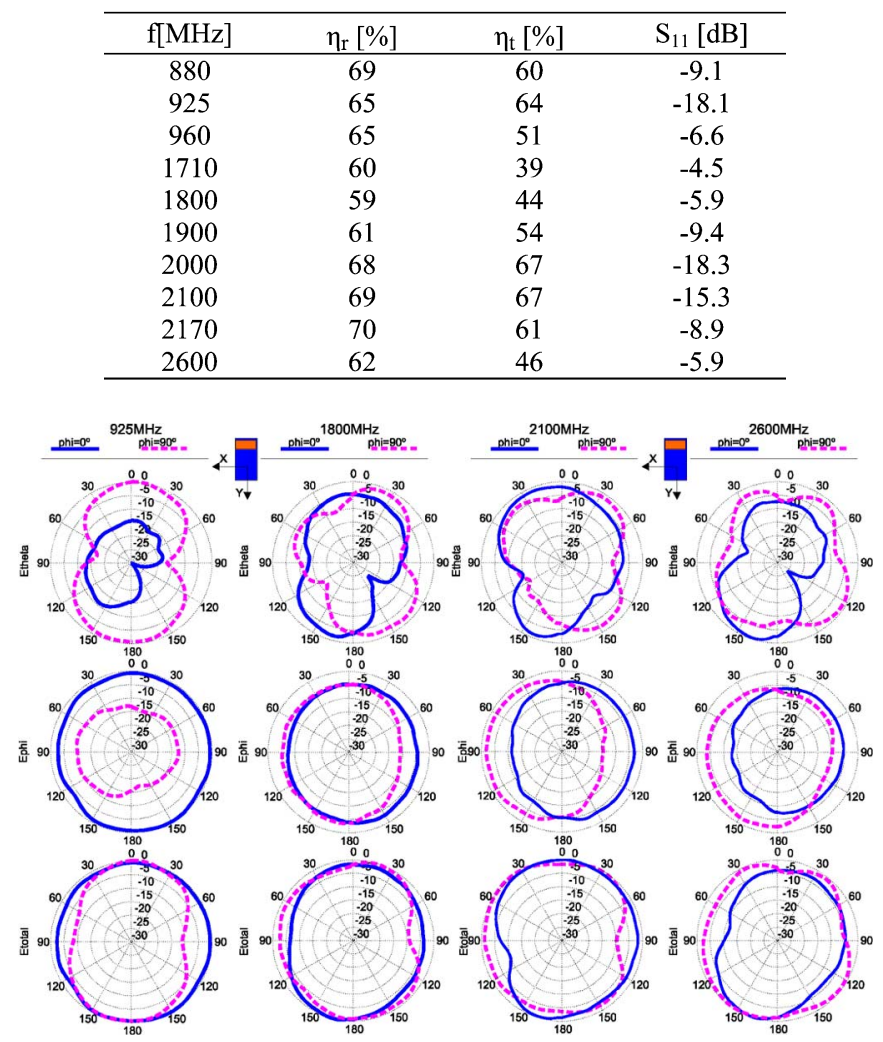

Fig. 16. Measured radiation cuts at 900, 1800, 2100, and $2600 \mathrm{MHz}$. Measured maximum gain at each frequency is $1.3,0.7,2.7$, and $0.85 \mathrm{dBi}$.

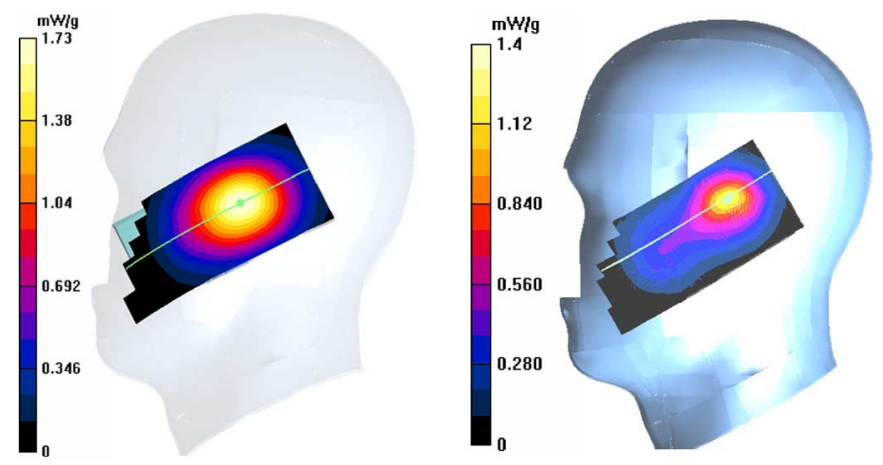

Fig. 17. Measured SAR distribution at right cheek position $900 \mathrm{MHz}$ (left) and $1800 \mathrm{MHz}$ (right).

Table I shows the measured $\eta_{\mathrm{r}}$ and $\eta_{\mathrm{t}}$. Even the existence of several cell-phone components, $\eta_{\mathrm{t}}$ can fulfil mobile service requirements.

Radiation cuts have been measured at 900, 1800, 2100, and $2600 \mathrm{MHz}$ (Fig. 16). Dipole-type radiation pattern can be observed at $900 \mathrm{MHz}$ determined by the ground plane mode: omnidirectional at $\varphi=0^{\circ}$ having linear polarization following $\mathrm{y}$-axis. Radiation patterns at higher frequencies present a larger directivity due to the larger electrical size of the ground plane.

Finally, specific absorption rate (SAR) in passive mode has been tested using Dasy-4 at Fractus-Lab. At GSM900 the max-
TABLE II

MEASURED SAR VALUES FOR THE ANTENNA PROTOTYPE OF FIG. 14

\begin{tabular}{ccc}
\hline frequency $[\mathrm{MHz}]$ & SAR $1 \mathrm{~g}[\mathrm{~mW} / \mathrm{g}]$ & SAR $10 \mathrm{~g}[\mathrm{~mW} / \mathrm{g}]$ \\
\hline 900 & 1.61 & 1.15 \\
1710 & 0.92 & 0.56 \\
1800 & 0.88 & 0.55 \\
1900 & 1.23 & 0.74 \\
\hline
\end{tabular}

imum transmit power is $33 \mathrm{dBm}$; however, a transmit channel uses only $1 / 8$ of a time slot. This results in $24 \mathrm{dBm}$ which is the power of a continuous wave to test SAR. Similar procedure is done at GSM1800; in this case, maximum transmit power is 30 $\mathrm{dBm}$. Thus, SAR is tested using $21 \mathrm{dBm}$.

SAR passive testing is indicative of a preliminary measure since SAR is finally tested with an active device. However, it is interesting to test in a passive way to analyze if the antenna may pose a SAR problem. For example, from this passive data (Table II and Fig. 17) some conclusions can be obtained.

a) At the low frequencies $(900 \mathrm{MHz})$, the hot-spot (maximum SAR value) is located at the centre of the ground plane confirming again that the ground plane mode determines radiation. The slot is weakly excited, meaning that it is not an issue for SAR.

b) At the higher frequencies, the hot-spot in mainly fixed by the slot on the ground plane since in this case the slot is excited, that is, SAR is more antenna dependent [17]. This is useful information since SAR can be dramatically reduced at higher bands by placing the antenna at the opposite short edge of the ground plane $\left(180^{\circ}\right.$ rotation of the handset) [22].

\section{CONCLUSION}

The concept based on a PIFA-slot has been shown to be useful to design multiband handset antennas where the number of frequency bands is given by the sum of the bands given by each radiator. Moreover, said bands can be controlled independently which adds an extra freedom design.

Component interaction has been analyzed showing that: a) the speaker mainly affects the slot radiator (introduces mismatch and losses) but its negative effect can be minimized by placing the speaker near the short-edge of the slot, b) battery affects the PIFA causing a detuning and introduce losses, c) the display is a critical component which should keep the slot free. This means that for planar handset antennas such as monopoles or slots, component interaction should be carefully taken into account. Although PIFA type occupies more space, components can be placed at the other part of the ground plane with a minimum impact on the performance of the antenna.

Thanks to the slot radiator, the PIFA volume can be reused to add more bands; for this research, an extra band centered at S-DBM has been added to finally design a pentaband prototype at GSM900, 1800, 1900, UMTS, and S-DMB. The total antenna volume results in only $39 \times 11 \times 2(\mathrm{~h}) \mathrm{mm}^{3}$. Results for total efficiency taking into account several components (battery, display, speaker, camera, and phone covers) are satisfactory and make this concept very attractive for the new generation of low-profile multiband handset phones. 


\section{REFERENCES}

[1] T. Taga and K. Tsunekawa, "Performance analysis of a built-in planar inverted-F antenna for $800 \mathrm{MHz}$ band portable radio units," IEEE Trans. Sel. Areas Commun., vol. SAC-5, no. 5, pp. 921-929, Jun. 1987.

[2] C. Puente, J. Romeu, C. Borga, and J. Anguera, "Multilevel antennas," patent Appl. WO 01/22528, Sep. 20, 1999.

[3] D. Manteuffel, A. Bahr, and I. Wolff, "Investigation on integrated antennas for GSM mobile phones," presented at the Millennium Conf. on Antennas and Propag., Davos, Switzerland, Apr. 2000.

[4] T. Y. Wu and K. L. Wong, "On the impedance bandwidth of a planar inverted-F antenna for mobile handsets," Microw. Opt. Technol. Lett., vol. 32, pp. 249-251, Feb. 20, 2002.

[5] K. L. Virga and Y. Rahmat-Samii, "Low-profile enhanced-bandwidth PIFA antennas for wireless communications packaging," IEEE Trans. Microw. Theory Tech., vol. 45, no. 10, pp. 1879-1888, Oct. 1997.

[6] C. R. Rowell and R. D. Murch, "A compact PIFA suitable for dualfrequency 900/1800-MHz operation," IEEE Trans. Antennas Propag., vol. 46, no. 4, pp. 596-598, Apr. 1998.

[7] J. Ollikainen, M. Fischer, and P. Vainikainen, "Thin dual-resonant stacked shorted patch antenna for mobile communications," Electron. Lett., vol. 35, no. 6, pp. 437-438, Mar. 18, 1999.

[8] Y. X. Guo, M. Y. W. Chia, and Z. N. Chen, "Miniature built-in quadband antennas for mobile handsets," IEEE Antennas Wireless Propag. Lett., vol. 2, pp. 30-32, 2003.

[9] B. Sanz-Izquierdo, J. Batchelor, and R. Langley, "Multiband printed PIFA antenna with ground plane capacitive resonator," Electron. Lett., vol. 40, no. 22, pp. 1391-1392, Oct. 28, 2004.

[10] Y. J. Cho, S. H. Hwang, and S. O. Park, "A dual-band internal antenna with a parasitic patch for mobile handsets and the consideration of the handset case and battery," IEEE Antennas Wireless Propag. Lett., vol. 4, pp. 429-432, 2005.

[11] M. Martínez-Vázquez, O. Litschke, M. Geissler, D. Heberling, A. M. Martínez-González, and D. Sánchez-Hernández, "Integrated planar multiband antennas for personal communication handsets," IEEE Trans. Antennas Propag., vol. 54, no. 2, pp. 389-391, Feb. 2006.

[12] P. Lindberg and E. Öjefors, "A bandwidth enhancement technique for mobile handset antennas using wavetraps," IEEE Trans. Antennas Propag., vol. 54, no. 8, pp. 2226-2233, Aug. 2006.

[13] B. N. Kim, S. O. Park, Y. S. Yoon, J. K. Oh, K. J. Lee, and G. Y. Koo, "Hexaband planar inverted-F antenna with novel feed structure for wireless terminals," IEEE Microw. Wireless Compon. Lett, vol. 6, pp. 66-69, 2007

[14] B. Jung, J. S. Lee, M. J. Park, Y. S. Chung, F. J. Harackiewicz, and B. Lee, "TDMB-AMPS-GSM-DCS-PCS-SDMB internal antenna using parasitic element with switching circuit," Electron. Lett., vol. 42, pp. 734-736, Jun. 22, 2006.

[15] K. R. Boyle and P. J. Massey, "Nine band antenna system for mobile phones," Electron. Lett., vol. 42, no. 5, pp. 265-266, Mar. 2006.

[16] K. L. Wong, Planar Antennas for Wireless Communication, ser. Wiley Series in Microwave and Optical Engineering, K. Chang, Ed. New York: Wiley, 2003.

[17] P. Vainikainen, J. Ollikainen, O. Kivekäs, and I. Kelander, "Resonator-based analysis of the combination of mobile handset antenna and chassis," IEEE Trans. Antennas Propag., vol. 50, no. 10, pp. 1433-1444, Oct. 2002.

[18] R. Hossa, A. Byndas, and M. E. Bialkowski, "Improvement of compact terminal antenna performance by incorporating open-end slots in ground plane," IEEE Microw. Wireless Compon. Lett., vol. 14, no. 6 , pp. 283-285, Jun. 2004.

[19] M. F. Abedin and M. Ali, "Modifying the ground plane and its effect on planar inverted-F antennas (PIFAs) for mobile phone handsets," IEEE Antennas Wireless Propag. Lett., vol. 2, pp. 226-229, 2003.

[20] J. Anguera, I. Sanz, A. Sanz, A. Condes, D. Gala, C. Puente, and J. Soler, "Enhancing the performance of handset antennas by means of groundplane design," presented at the IEEE Int. Workshop on Antenna Technology: Small Antennas and Novel Metamaterials (IWAT), New York, Mar. 2006.

[21] J. Anguera, A. Cabedo, C. Picher, I. Sanz, M. Ribó, and C. Puente, "Multiband handset antennas by means of groundplane modification," presented at the IEEE Antennas Propagation Society Int. Symp., Honolulu, HI, Jun. 2007.

[22] A. Cabedo, J. Anguera, C. Picher, M. Ribö, and C. Puente, "Multiband handset antenna combining PIFA, slots, and ground plane modes," IEEE Trans. Antennas Propag., vol. 57, no. 9, pp. 2526-2533, Sep. 2009.
[23] C. Picher, J. Anguera, A. Cabedo, C. Puente, and S. Kahng, "Multiband handset antenna using slots on the ground plane: Considerations to facilitate the integration of the feeding transmission line," Progr. Electromagn. Res. C, vol. 7, pp. 95-109, 2009.

[24] R. F. Harrington and J. R. Mautz, "Theory of characteristic modes for conducting bodies," IEEE Trans. Antennas Propag., vol. 19, pp. 622-628, Sep. 1971.

[25] E. Antonino, C. A. Suárez, M. Cabedo, and M. Ferrando, "Wideband antenna for mobile terminals based on the handset PCB resonance," Microw. Opt. Technol. Lett., vol. 48, no. 7, pp. 1408-1411, Jul. 2006.

[26] M. Cabedo, E. Antonino, A. Valero, and M. Ferrando, "The theory of characteristic modes revisited: A contribution to the design of antennas for modern applications," IEEE Antennas Propag. Mag., vol. 49, no. 5 , pp. 52-68, Oct. 2007.

[27] M. Cabedo, E. Antonino, V. Rodrigo, and C. Suárez, "Análisis modal de un plano de masa radiante doblado y con una ranura para terminales móviles," presented at the XXI National Symp. URSI'06, Oviedo, Spain, 2006, Sep..

[28] C. Di Nallo and A. Faraone, "Multiband internal antenna for mobile phones," Electron. Lett., vol. 41, pp. 514-515, 2005.

[29] C. Lin and K. L. Wong, "Printed monopole slot antenna for internal multiband mobile phone antenna," IEEE Trans. Antennas Propag., vol. 55, no. 2, pp. 3690-3697, Dec. 2007.

[30] S. Kahng, "The rectangular power-bus with slits GA-optimized to damp resonances," IEEE Trans. Antennas Propag., vol. 55, no. 6, pp. 1892-1895, Jun. 2007

[31] S. Hong, W. Kim, H. Park, S. Kahng, and J. Choi, "Design of an internal multiresonant monopole antenna for GSM900/DCS1800/US PCS/S-DMB operation," IEEE Trans. Antennas Propag., vol. 56, no. 5, pp. 1437-1443, May 2008.

[32] R. Quintero and C. Puente, "Multilevel and space-filling ground-planes for miniature and multiband antennas," patent appl. WO 03/023900, Sep. 13, 2001.

[33] J. Anguera and C. Puente, "Shaped groundplane for radio apparatus," patent appl. WO 06/ 070017, Dec. 29, 2005.

[34] J. Anguera, I. Sanz, J. Mumbrú, and C. Puente, "Multiband handset antenna behavior by combining PIFA and a slot radiators," presented at the IEEE Antennas Propag. Society Int. Symp., Honolulu, HI, Jun. 2007.

[35] C. Lin and K. L. Wong, "Internal hybrid antenna for multiband operation in the mobile phone," Microw. Opt. Tech. Lett., vol. 50, no. 1, pp. 38-42, Jan. 2008.

[36] S. Kumar, L. Shafai, and N. Jacob, "Investigation of wide-band microstrip slot antenna," IEEE Trans. Antennas Propag., vol. 52, no. 3, pp. 865-872, Mar. 2004.

[37] K. L. Wong, Compact and Broadband Microstrip Antennas, ser. Wiley Series in Microwave and Optical Engineering, K. Chang, Ed. New York: Wiley, 2002.

[38] B. N. Kim, S. O. Park, Y. S. Yoon, J. K. Oh, K. J. Lee, and G. Y Koo, "Hexaband planar inverted-F antenna with novel feed structure for wireless terminals," IEEE Antennas Wireless Propag. Lett., vol. 6 , pp. 66-68, 2007.

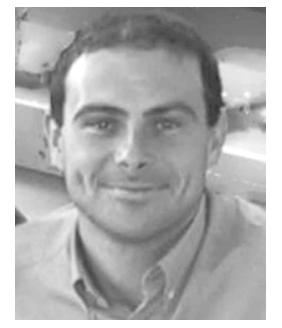

Jaume Anguera (S'99-M'03-SM'09) was born in Vinaròs, Spain, in 1972. He received the Technical Ingeniero degree in electronic systems and Ingeniero degree in electronic engineering from the Ramon Llull University (URL), Barcelona, Spain, in 1994 and 1997, respectively, and the Ingeniero and Ph.D. degrees in telecommunication engineering from the Polytechnic University of Catalonia (UPC), Barcelona, Spain, in 1998 and 2003, respectively.

From 1998 to 2000, he joined the Electromagnetic and Photonic Engineering Group (EEF), Signal Theory and Communications Department, UPC, as a Researcher in microstrip fractal-shaped antennas. In 1999, he was a Senior Researcher at Sistemas Radiantes, Madrid, Spain, where he was involved in the design of a dual-frequency dual-polarized fractal-shaped microstrip patch array for mobile communications. In the same year, he became an Assistant Professor at the Department of Electronics and Telecommunications, Universitat Ramon Llull-Barcelona, where he is currently teaching antenna theory. Since 2000, he has been with Fractus, S.A., Barcelona, Spain, where he holds the position of R\&D Manager. At Fractus, he leads projects on antennas for base station systems, antennas for automotion, handset and wireless antennas. His research interest are multiband and small antennas, microstrip patch arrays, feeding network architectures, broadband matching networks, array pattern synthesis with genetic algorithms, diversity antenna systems, electromagnetic dosimetry, and handset antennas. 
He is a Leading Engineer for the Innovation Antenna Group. From September 2003 to May 2004, he was with Fractus-Korea (Republic South of Korea) where he was managing projects for miniature and multiband antennas for handset and wireless applications. Since 2005 , he has been leading research projects in the antenna field for handset and wireless applications in a frame of industry-university collaboration: Fractus company and the Department of Electronics and Communications, Universitat Ramon Llull-Barcelona, Spain. He holds more than 27 patents on fractal an other related antennas. He is the author/coauthor of more than 120 journal, international, and national conference papers and he has directed more than 50 bachelor and master thesis.

Dr. Anguera was member of the Fractal team that in 1998 received the European Information Technology Grand Prize from the European Council for the Applied Science an Engineering and the European Commission for the fractal-shaped antenna application to cellular telephony. He was the 2003 Finalist for the Best Doctoral Thesis (Fractal and Broadband Techniques on Miniature, Multifrequency, and High-Directivity Microstrip Patch Antennas) on UMTS (this prize has been promoted by "Technology plan of UMTS promotion" given by Telefónica Móviles España). He was named one of the New faces of Engineering 2004 by the IEEE. In the same year, he received the Best Doctoral Thesis (Ph.D.) in "Network and BroadBand Services" (XXIV Prize Edition "Ingenieros de Telecomunicación") organized by Colegio Oficial de Ingenieros de Telecomunicación (COIT) and ONO Company. He is reviewer for the IEEE TRANSACTIONS AND ANTENNAS AND PROPAGATION, IEEE Antennas And Wireless Propagation LetTers, Progress in Electromagnetic Research (PIER), IEE Electronics Letters, and the ETRI Journal (Electronics and Telecommunications Research Institute, South Korea). His biography is listed in Who's Who in the World, Who's Who in Science and Engineering, Who's Who in Emerging Leaders and in IBC (International Biographical Center, Cambridge-England).

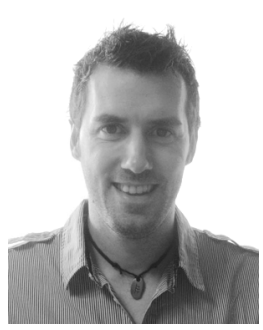

Iván Sanz was born in Oviedo, Spain, in 1974. He received the Ingeniero degree in telecommunication engineering from the Polytechnic University of Catalonia (UPC), Barcelona, Spain, in 2008.

He joined Fractus S.A., Barcelona, Spain, in 2005. He has been involved in several investigation projects about the application of the fractal technology in the design of miniature multiband antennas.

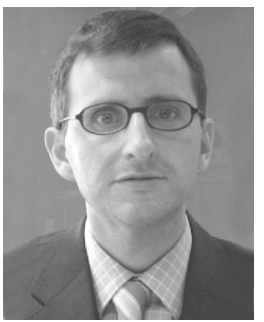

Josep Mumbrú was born in Barcelona, Spain, in 1971. He received the Ingeniero degree in telecommunication engineering (with specialization in communication systems) and the Ingeniero degree in electronics from the Polytechnic University of Catalonia (UPC), Barcelona, Spain, in 1995 and 1996, respectively, and the M.Sc. degree in electrical engineering and the Ph.D. degree in electrical engineering and social science from the California Institute of Technology (Caltech), Pasadena, in 1998 and 2002 , respectively.

From 1997 to 2002, he was Research and Teaching Assistant in the Optical Information Processing Group, Caltech. He conducted research work in the fields of holographic data storage for optical memories, holographic imaging systems and components for WDMA optical fiber network. He also collaborated with Holoplex Inc., in the development of next generation systems for optical data storage. Since 2002 he has been with Fractus S.A., Barcelona, where he holds the position of R\&D and IPR Manager. At Fractus, he has contributed to the development of the fractal antenna technology and their applications to mobile communication and wireless connectivity devices, and to the growth and strengthening of Fractus patent portfolio.

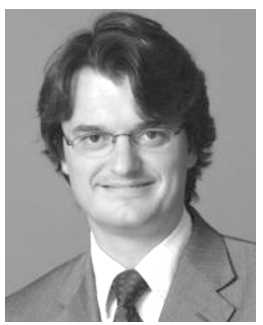

Carles Puente (M'92) received the M.Sc. degree from the University of Illinois at Urbana-Champaign, in 1994 and the Ph.D. degree from Polytechnic University of Catalonia (UPC), Barcelona, Spain, in 1997.

From 1994 to 1999 , he worked with the faculty of Electromagnetic and Photonic Engineering, UPC, on pioneering developments of fractal technology applied to antennas and microwave devices. He is a co-founder of Fractus, S.A., Barcelona, Spain, and currently leads its Antenna Technology Research Team, with responsibility for the company's intellectual property portfolio development and antenna development. He is also a Professor at UPC, Barcelona, Spain, where he started researching fractal-shaped antennas while a student in the late 1980s. He has authored more than 50 invention patents and over 90 scientific publications in fractal and related antenna technologies.

Dr. Puente was awarded the Best Doctoral Thesis in Mobile Communications 1997 by the COIT, the European Information Society Technology Grand Prize from the European Commission in 1998, and the Premi Ciutat de Barcelona in 1999. He and his team at Fractus where awarded the Technology Pioneer distinction by the World Economic Forum in 2005. 